\title{
Indoor secondhand tobacco smoke emission levels in six Lebanese cities
}

\author{
Georges Saade, ${ }^{1}$ Andrew B Seidenberg, ${ }^{2}$ Vaughan W Rees, ${ }^{2}$ Zaher Otrock, ${ }^{3}$ \\ Gregory N Connolly ${ }^{2}$
}

${ }^{1}$ Faculty of Public Health, Lebanese University, Beirut, Lebanon

${ }^{2}$ Harvard School of Public Health, Division of Public Health

Practice, Boston,

Massachusetts, USA

${ }^{3}$ Department of Pathology, American University of Beirut, Beirut, Lebanon

\section{Correspondence to}

Dr Vaughan Rees, Harvard School of Public Health, Division of Public Health Practice, Landmark Building, Level 3 East, 677 Huntington Ave, Boston, MA 02115, USA:

vrees@hsph.harvard.edu

Received 8 April 2009 Accepted 25 November 2009

\section{ABSTRACT}

Background To date, Lebanon has failed to enact comprehensive clean indoor air laws despite ratification of the Framework Convention on Tobacco Control (FCTC), which calls for the protection of non-smokers from exposure to secondhand tobacco smoke (SHS). Complicating the problem of SHS exposure in Lebanon is the widespread use of the tobacco water-pipe. While most research on SHS has involved cigarette smoking as a source of emissions, other sources, including tobacco water-pipes, may be an important contributor.

Methods $\mathrm{PM}_{2.5}$ concentrations $\left(\mu \mathrm{g} / \mathrm{m}^{3}\right)$ were measured in a sample of 28 public venues located in six major Lebanese cities. Active smoker density (number of smokers/100 $\mathrm{m}^{3}$ ) was calculated for both water-pipe and cigarette smokers. Venues were then categorised as having higher density of water-pipe smokers or higher density of cigarette smokers, and resultant emission levels were compared between the two groups.

Results Cigarette and water-pipe smoking was observed in 14 venues, while cigarette smoking only and water-pipe smoking only were found in 12 venues and one venue, respectively. Among all smoking-permitted venues, the mean $\mathrm{PM}_{2.5}$ concentration was $342 \mu \mathrm{g} / \mathrm{m}^{3}$. Venues with a higher density of water-pipe smokers (n $=14$ ) showed a similar median $\mathrm{PM}_{2.5}$ concentration $\left(349 \mu \mathrm{g} / \mathrm{m}^{3}\right)$ compared with venues with a higher density of cigarette smokers ( $n=13 ; 241 \mu \mathrm{g} / \mathrm{m}^{3} ; \mathrm{p}=0.159$ ). The mean $\mathrm{PM}_{2.5}$ concentration in the single venue with a voluntary smoke-free policy was $6 \mu \mathrm{g} / \mathrm{m}^{3}$.

Conclusions Despite ratification of the FCTC in 2005, both cigarette and water-pipe smoking are commonly practised in enclosed public places throughout Lebanon, leading to unsafe levels of indoor particulate pollution. Smoke-free policies are needed in Lebanon to protect the public's health, and should apply to all forms of tobacco smoking.

\section{INTRODUCTION}

Exposure to secondhand tobacco smoke (SHS) is a major, preventable cause of premature death and disease in non-smokers. ${ }^{1}$ SHS contains over 2500 chemical constituents, of which approximately 250 are known to be toxic or carcinogenic. ${ }^{2}$ Exposure to SHS among children is a major paediatric problem and is associated with increased risk of sudden infant death syndrome, acute respiratory infections, ear problems and worsening of asthma symptoms. ${ }^{1}$ While most research on SHS has involved cigarettes as a source of emissions, other sources, including tobacco water-pipes, may be an important contributor. ${ }^{3}$ Tobacco water-pipes, also known as hookah, involve a unique design in which tobacco smoke is drawn through a water bubbler before reaching the smoker. The tobacco used in waterpipes, often known as moassel, is a highly sweetened and flavoured blend with high moisture content. The tobacco is heated by burning charcoal, and it releases a caramelised sugar or fruit-scented aroma as it is smoked. ${ }^{4}$ Water-pipe smoking is often regarded by its users as less harmful than cigarettes, 56 possibly because of its unique design, the flavoured tobacco use and scented SHS emissions.

Many of the constituents found in cigarette smoke have also been identified in water-pipe emissions. ${ }^{7}$ Both sources of SHS carry respirable suspended particles. ${ }^{3910}$ Limited laboratory testing has suggested that particulate emissions arising from active water-pipe smoking may be comparable to or greater than cigarette emissions. Water-pipe sessions lasting 30 minutes may generate similar emission levels as a single cigarette smoked for about 10 minutes. ${ }^{3}$

The World Health Organization has established air quality guidelines $(\mathrm{AQG})^{11}$ for particulate matter based on the scientific evidence demonstrating a link between exposure to fine particulate air pollution and adverse health outcomes including cardiopulmonary events $^{12}$ and mortality. ${ }^{13}$ To protect the public's health, the current WHO guideline for $\mathrm{PM}_{2.5}$ pollution is a daily mean exposure of $25 \mu \mathrm{g} / \mathrm{m}^{3} .11$ However, fine particulate pollution levels within indoor public venues that permit smoking have been found to exceed this recommendation by severalfold. ${ }^{9}$

To address the widespread public health problem of exposure to SHS, a growing number of countries have enacted legislation prohibiting indoor smoking in public places. To encourage broader adoption of such policies, Article 8 of WHO's Framework Convention on Tobacco Control (FCTC), the world's first global public health treaty, calls for implementation of effective measures to protect all people from exposure to SHS. ${ }^{14}$ Lebanon ratified the FCTC in December of 2005; however, no restrictions on smoking in workplaces, public transit or indoor public places have yet been enacted.

A comprehensive policy response to SHS exposure first requires the development of an appropriate research base to document the nature and extent of the problem. At the current time, only one known investigation has monitored air quality in environments in which smoking occurs in Lebanon. ${ }^{9}$ However, the number of Lebanese venues sampled in this investigation was relatively small $(\mathrm{n}=9)$ and no information on the number of cigarette and water-pipe smokers in these venues unlocked scheme, see http:// tobaccocontrol.bmi.com/site/ about/unlocked.xhtml 
was reported. Further, data demonstrating the contribution of water-pipe smoking, a favoured form of tobacco use in Lebanon, to SHS smoke emissions are urgently needed. The present study aimed to document the prevalence of indoor smoking-both cigarette and water-pipe-and corresponding indoor air quality in Lebanon. A secondary aim was to compare air quality between venues where mostly cigarette smoking occurred versus venues with mostly water-pipe smoking. Because water-pipe and cigarette emissions cannot be measured separately in venues where both types of smoking occur, venues were categorised as having either higher water-pipe or higher cigarette smoker densities, and emissions levels among these two venue types were compared.

\section{MATERIALS AND METHODS}

Between June and September 2008, indoor air quality was measured inside 28 enclosed public places in the Lebanese cities of Antelias, Batroun, Beirut, Koura, Saida and Tripoli. The six cities were selected using a purposive strategy, intended to reflect geographical and economic diversity: Antelias is located in the Mount Lebanon region; the northern city of Batroun is known for its entertainment and night life; the central coastal city of Beirut is the nation's capital and largest city; Koura is an intellectual district in the north; Saida is the nation's third largest city and is located in the south; the northern city of Tripoli is the country's second largest city.

Study venues were also purposively selected, and included a range of hospitality venues, including cafes, restaurants, pubs and a night club. Hospital cafeterias and a shopping mall were also included to diversify the type of venues sampled. Within each city, efforts were made to visit hospitality venues in at least two popular entertainment districts. For logistical reasons, venues were selected on the basis of convenience by the research staff while attempting nevertheless to recruit venues that were representative in terms of size, location and clientele, for each region. To ensure the sampling of at least one smoke-free venue, a cafe with a known voluntary smoke-free policy was included.

The TSI SidePak AM510 Personal Aerosol Monitor (TSI, Inc, St Paul, MN, USA) was used to sample and record the levels of respirable suspended particles. The Sidepak uses a sampling pump to draw air into the device and the concentration of particulate matter is determined using light scattering technology. ${ }^{9}$ A $2.5-\mu \mathrm{m}$ impactor was employed to measure the levels of particulate matter with a mass-median aerodynamic diameter $\leq 2.5 \mu \mathrm{m}\left(\mathrm{PM}_{2.5}\right)$. A Sidepak calibration factor of 0.32 was used. The data logging interval was set to 1 minute and the device was turned on and off inside each venue to prevent contamination with outside air.

The air monitoring device was positioned in a central location inside each venue and air within occupants' normal breathing area was sampled. Data were collected unobtrusively to ensure natural behaviour of patrons and employees. The number of cigarette and water-pipe smokers was also counted upon entry into each venue and each subsequent 15-minute interval. A minimum of 15 minutes was spent monitoring air quality in each venue, and at least two such counts were performed to calculate mean number of smokers (cigarette and water-pipe).

The internal volume of each venue was measured using an AEG UM 15L Sonic Measure (AEG Elektrowerkzeuge, Winnenden, Germany).

\section{RESULTS}

Both cigarette smoking and water-pipe smoking were present in 14 of the venues, in contrast to 12 venues in which cigarette smoking only occurred. Water-pipe smoking alone was found in a single venue. Smoking (either cigarettes or water-pipe) thus was observed in all venues except the one cafe with a known voluntary smoke-free policy.

The number of cigarette smokers in each of the smokingpermitted venues ranged from 0 to 175, while the number of water-pipe smokers ranged from 0 to 72 . Across all smokingpermitted venues, the median number of cigarette smokers was 3.0 and water-pipe smokers was 2.3. The active water-pipe and cigarette smoker densities ( $\mathrm{ASD}_{\mathrm{WP}}$ and $\mathrm{ASD}_{\mathrm{CIG}}$, respectively) were calculated for each venue by dividing the mean number of water-pipe or cigarette smokers by venue volume $\left(100 \mathrm{~m}^{3}\right)$.

Mean $\mathrm{PM}_{2.5}$ levels among all smoking-permitted venues ranged from $28 \mu \mathrm{g} / \mathrm{m}^{3}$ to $1324 \mu \mathrm{g} / \mathrm{m}^{3}$ and the overall mean for these venues was $342 \mu \mathrm{g} / \mathrm{m}^{3}$. In the only smoke-free venue, the mean $\mathrm{PM}_{2.5}$ concentration was $6 \mu \mathrm{g} / \mathrm{m}^{3}$, which was the lowest mean $\mathrm{PM}_{2.5}$ level observed for all venues visited. Four of the venues sampled (1, 2, 3 and 21) hosted festive Ramadan events within enclosed tents. Smoking was present in each and high levels of air pollution were found. The mean $\mathrm{PM}_{2.5}$ level for these four venues was $538 \mu \mathrm{g} / \mathrm{m}^{3}$. ASD TOTAL was calculated by dividing the total number of smokers (water-pipe plus cigarette smokers) by venue volume $\left(100 \mathrm{~m}^{3}\right)$. Among all venues sampled, $\mathrm{ASD}_{\text {TOTAL }}$ was positively correlated with $\mathrm{PM}_{2.5}$ concentration (Spearman's $r=0.467 ; p=0.012$ ).

The smoking-permitted venues were then classified into two groups: those with a higher density of water-pipe smokers ( $\mathrm{n}=$ 14) and those with a higher density of cigarette smokers $(n=13)$. Because it is impossible to separately measure the emissions from water-pipes and cigarettes in venues with both sources of pollution, the strategy to compare venues on the basis of smoker density - cigarette versus water-pipe-is a practical approach to better understand how each source of SHS contributes to a venue's overall air quality. Table 1 presents $\mathrm{PM}_{2.5}$ levels for each venue in decreasing order, separated by venues with greater water-pipe smoking density, cigarette smoking density and no observed smoking. Median $\mathrm{PM}_{2.5}$ levels were found to be greater for venues with higher $\mathrm{ASD}_{\mathrm{WP}}\left(349 \mu \mathrm{g} / \mathrm{m}^{3}\right)$ compared with those with higher $\mathrm{ASD}_{\mathrm{CIG}}\left(241 \mu \mathrm{g} / \mathrm{m}^{3}\right)$, but this difference was not statistically significant (two-sample Wilcoxon rank sum test $z=$ $-1.407 ; \mathrm{p}=0.159$ ). Figure 1 shows $\mathrm{PM}_{2.5}$ concentrations for venues with greater water-pipe and cigarette smoker densities, with the median for each group represented in a horizontal line. Also detailed are the relative proportions of water-pipe and cigarette smokers observed in each venue.

\section{DISCUSSION}

The present study assessed indoor air quality among a sample of enclosed public places in multiple cities in Lebanon. Despite ratification of the FCTC by the Lebanese government in December 2005, which calls for the adoption of measures to protect the public from 'exposure to tobacco smoke in indoor workplaces $^{14}$ (eg, bars and restaurants), the absence of clean indoor air laws has allowed the continuation of widespread indoor smoking. Cigarette and/or water-pipe use was observed in 27 of the 28 venues visited. Among these venues the mean $\mathrm{PM}_{2.5}$ concentration was $342 \mu \mathrm{g} / \mathrm{m}^{3}$. In contrast, the mean $\mathrm{PM}_{2.5}$ concentration in the one smoke-free venue was $6 \mu \mathrm{g} / \mathrm{m}^{3}$.

To put the measured $\mathrm{PM}_{2.5}$ levels into perspective, a comparison can be made to the WHO's air quality guideline. ${ }^{11}$ According to this guideline, exposure to $\mathrm{PM}_{2.5}$ pollution should not exceed a daily average of $25 \mu \mathrm{g} / \mathrm{m}^{3}$ (see figure 1 ). Among the 27 smokingpermitted venues, the overall mean $\mathrm{PM}_{2.5}$ concentration far exceeded this value, with the most polluted venue having a mean 
Table 1 Summary statistics for each venue visited

\begin{tabular}{|c|c|c|c|c|c|c|}
\hline Venue No & $\begin{array}{l}\mathrm{PM}_{2.5} \text { levels } \\
\left(\mu \mathrm{g} / \mathrm{m}^{3}\right)\end{array}$ & $\begin{array}{l}\operatorname{ASD}_{\mathrm{wP}}(\text { No of } \\
\text { smokers } / 100 \mathrm{~m}^{3} \text { ) }\end{array}$ & $\begin{array}{l}\mathrm{ASD}_{\text {CIG }}(\text { No of } \\
\text { smokers } / 100 \mathrm{~m}^{3} \text { ) }\end{array}$ & Volume $\left(\mathrm{m}^{3}\right)$ & Venue type & City \\
\hline \multicolumn{7}{|c|}{ Venues with greater $A S D_{W P}$} \\
\hline 1 & 723 & 4.25 & 0.65 & 1683 & Cafe-restaurant & Antelias \\
\hline 3 & 540 & 3.03 & 1.13 & 2380 & Cafe-restaurant & Antelias \\
\hline 4 & 523 & 2.14 & 1.44 & 749 & Restaurant & Antelias \\
\hline 5 & 505 & 1.63 & 0.13 & 796 & Cafe-restaurant & Antelias \\
\hline 8 & 342 & 1.75 & 0.20 & 646 & Cafe-restaurant & Beirut \\
\hline 9 & 304 & 2.53 & 1.43 & 91 & Cafe & Saida \\
\hline 10 & 260 & 1.76 & 0.33 & 598 & Cafe-restaurant & Beirut \\
\hline 11 & 233 & 2.67 & 1.33 & 75 & Cafe & Saida \\
\hline 12 & 228 & 3.46 & 0.58 & 433 & Cafe-restaurant & Antelias \\
\hline 16 & 506 & 0.00 & 1.58 & 557 & Pub-restaurant & Beirut \\
\hline 17 & 441 & 0.00 & 2.38 & 231 & Hospital cafeteria & Koura \\
\hline 18 & 366 & 1.80 & 2.73 & 183 & Cafe & Saida \\
\hline 19 & 316 & 0.00 & 1.40 & 358 & Cafe-restaurant & Beirut \\
\hline 20 & 252 & 0.00 & 3.11 & 106 & Cafe-restaurant & Beirut \\
\hline 21 & 241 & 0.00 & 0.80 & 287 & Cafe-restaurant & Saida \\
\hline 22 & 181 & 0.00 & 4.19 & 253 & Restaurant & Beirut \\
\hline 23 & 101 & 0.00 & 1.95 & 128 & Hospital cafeteria & Koura \\
\hline 24 & 93 & 0.00 & 3.85 & 273 & Pub-restaurant & Batroun \\
\hline 25 & 73 & 0.00 & 2.07 & 58 & Restaurant & Beirut \\
\hline 26 & 56 & 0.00 & 0.27 & 1125 & Cafe-restaurant & Beirut \\
\hline 27 & 28 & 0.00 & 0.10 & 3888 & Shopping mall & Beirut \\
\hline
\end{tabular}

$A S D_{\text {CIG }}$ active cigarette smoker density; $A S D_{W P}$, active water-pipe smoker density.

concentration of $1324 \mu \mathrm{g} / \mathrm{m}^{3}$. Owing to such elevated levels, individuals working in many of these venues, and thus exposed for prolonged periods, multiple times per week, are likely to be at risk of exposure to unsafe $\mathrm{PM}_{2.5}$ levels, as well as exposure to multiple toxic smoke constituents, including a number of known carcinogens. $^{2}$ The elevated levels of indoor air pollution are consistent with measurements taken within smoking-permitted venues in other countries and underscore the urgent need to
Figure 1 Mean $\mathrm{PM}_{2.5}$ levels and relative proportions of water-pipe and cigarette smokers observed for venues with greater water-pipe and cigarette smoker densities.

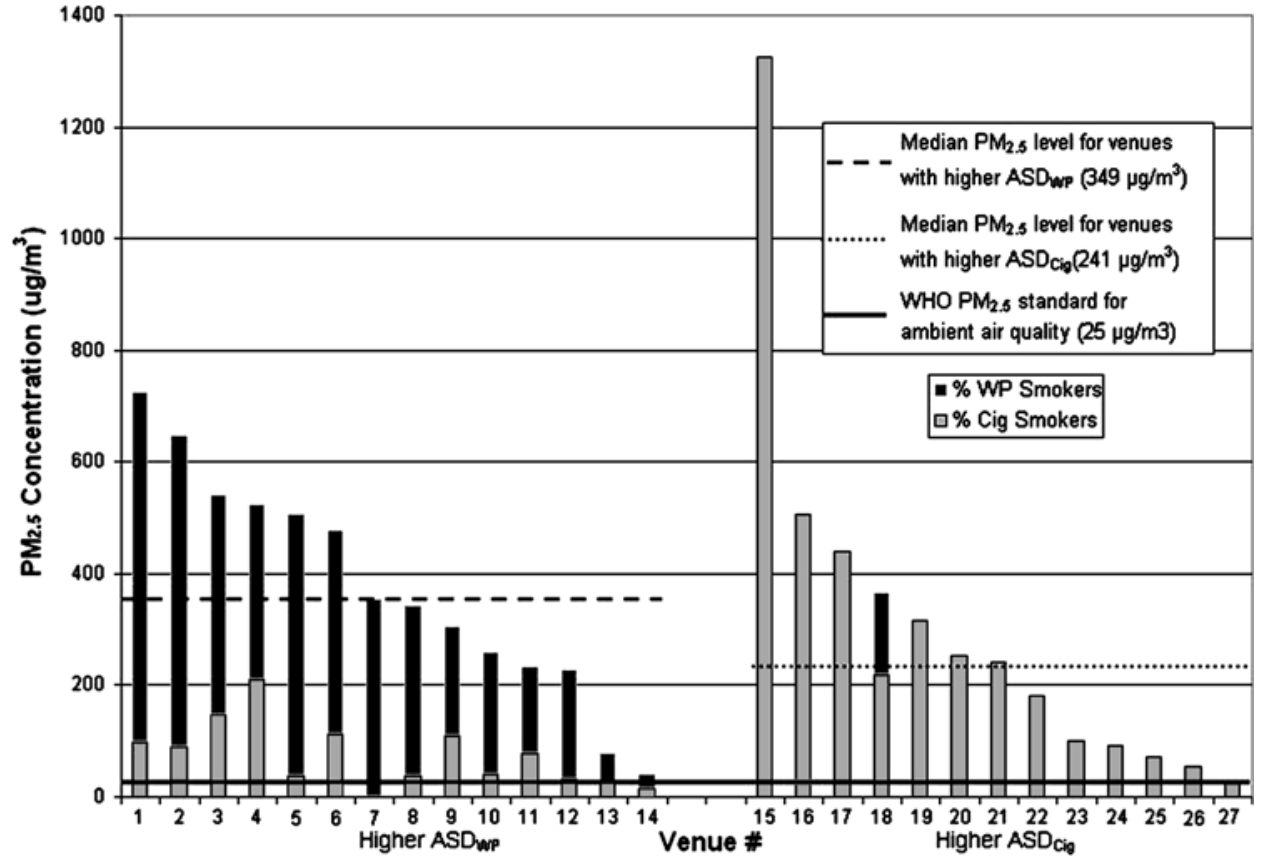


implement smoke-free policies to protect employees and patrons. For instance, measurements taken in Romania, Syria and Tunisia, had geometric mean levels of $386 \mu \mathrm{g} / \mathrm{m}^{3}, 372 \mu \mathrm{g} / \mathrm{m}^{3}$ and $328 \mu \mathrm{g} /$ $\mathrm{m}^{3}$, respectively. ${ }^{9}$ In jurisdictions that have enacted smoke-free legislation, significant declines in $\mathrm{PM}_{2.5}$ pollution ${ }^{15-17}$ and related health risks and outcomes ${ }^{18-20}$ have resulted after implementation.

A small, but growing, body of research has addressed waterpipe use and the resulting emissions, but there is still relatively little research documenting the effect of water-pipe use on indoor air quality in the field. The present study is among the first to report on indoor air quality in venues where water-pipe smoking occurs. Indoor water-pipe use was observed in approximately half of the venues visited. Water-pipe smoking has the potential to generate high levels of $\mathrm{PM}_{2.5}$ emissions. In the one venue where only water-pipe smoking was observed, the mean $\mathrm{PM}_{2.5}$ concentration was $355 \mu \mathrm{g} / \mathrm{m}^{3}$. Moreover, venues with greater density of water-pipe smokers had (non-significantly) higher levels of particulate pollution, compared to those with a greater density of cigarette smokers. The present data suggest that water-pipe smoking is a major contributor to indoor air pollution, and may contribute similar levels of $\mathrm{PM}_{2.5}$ as cigarette smoking in public venues. Water-pipe smoking produces high levels of carbon monoxide, which arise from the burning coal heat source. ${ }^{7}$ The measurement of carbon monoxide in addition to particulate matter would provide important additional information about air quality in venues in which waterpipes are used. Despite the potentially high SHS levels arising from indoor water-pipe use, there is no information on whether SHS arising from water-pipes is perceived as harmful by those exposed. Research has shown that water-pipe smoking is regarded as less harmful than cigarette smoking. ${ }^{5}{ }^{6}$ Further research is needed to establish whether SHS emissions of waterpipes also are perceived as less harmful than cigarettes.

The holiday of Ramadan occurred during the timeframe of the current investigation. During this holy month it is customary for many families to eat in the evenings in large enclosed 'Ramadan tents', where water-pipe smoking is common. Particulate pollution levels averaged $538 \mu \mathrm{g} / \mathrm{m}^{3}$ within the four venues hosting Ramadan events. Such unsafe levels are of particular concern given the presence of children in these venues. Smoking was also observed in other types of venues commonly frequented by children, such as hospital cafeterias, restaurants and cafes.

Limitations of the study design pose problems in generalising these findings to all venues within the six cities visited. These include the convenience selection of venues, seasonal bias and number of venues visited. Moreover, this study presents limitations in distinguishing between cigarette and water-pipe emissions and isolating their relative contributions to observed $\mathrm{PM}_{2.5}$ levels. A direct comparison between water-pipe and cigarette $\mathrm{PM}_{2.5}$ emissions would require separate measurements of each emission source while controlling for internal venue volume, air exchange rate and other factors influencing the aerodynamic behaviour of fine particles including smoker density and smoker puffing behaviour. $\mathrm{PM}_{2.5}$ may also arise from other sources such as ambient air pollution and cooking. Future research might partially resolve this problem by monitoring air quality in cigarette-only and water-pipe-only venues, as well as dual-use venues. However, this may be difficult to achieve (at least in Lebanon) because of the high co-occurrence of cigarette and water-pipe smoking. Further, making observations during the month of Ramadan could distort findings, as observance of the Ramadan holiday calls for abstinence from smoking until sundown, thus potentially diminishing SHS levels during daylight hours and increasing them at night. However, unsafe SHS levels were observed in most venues, covering both day and night-time sampling, and further research may confirm that indoor SHS levels continue to be unsafe outside of the Ramadan period.

\section{Conclusions}

Unsafe levels of indoor air pollution were found in public places in multiple cities, and indoor smoking was commonly found in various types of public venues in Lebanon. To fully protect the public's health from this source of indoor air pollution, smoking restrictions in Lebanon should also apply to venues where waterpipe smoking occurs. One challenge in protecting the public from SHS exposure in Lebanon might arise from the cultural significance of water-pipe use, which is popular throughout the Eastern Mediterranean Region. ${ }^{21}$ In the present study water-pipe smoking was observed in over half of the venues visited. Policies that prohibit smoking indoors are the most effective strategy to reduce non-smokers' exposure to SHS. Comprehensive clean indoor air laws, which completely ban all indoor smoking, regardless of smoking type or physical features of the venue, have received strong support in various countries ${ }^{22-24}$ and have contributed to reductions in adverse health outcomes. ${ }^{18-20}$ Moreover, neighbouring Syria recently announced a comprehensive clean indoor air law which includes water-pipe smoking. ${ }^{25} \mathrm{~A}$ comprehensive ban on indoor smoking in Lebanese workplaces would unambiguously communicate the risks associated with exposure to all forms of tobacco smoke. In the absence of a comprehensive ban, the health benefits that have been realised in countries prohibiting indoor smoking are unlikely to be realised in Lebanon. The signing and ratification of the FCTC by the Lebanese government is an important step in achieving the nation's public health goals and demonstrates a commitment to the protection of all who live there. However, the implementation of smoke-free legislation is needed to ensure full protection from this preventable public health problem.

\section{What this paper adds?}

Secondhand smoke is a major cause of preventable disease and mortality. To protect the public's health, WHO is encouraging nations to adopt smoking restrictions in public places through its Framework Convention on Tobacco Control (FCTC).

This study assessed the prevalence of cigarette and water-pipe smoking among a convenience sample of 28 enclosed public places in six Lebanese cities, and measured $\mathrm{PM}_{2.5}$ concentrations within those venues. Although the Lebanese government ratified the FCTC in 2005, tobacco smoking, particularly through the use of water-pipes, was observed in 27 out of the 28 of the venues sampled. Particulate pollution within the smokingpermitted venues was observed to be at unsafe levels, with an overall mean level of $342 \mu \mathrm{g} / \mathrm{m}^{3}$. Results also show that waterpipe and cigarette use often co-occur within the same venue. This can make separate measurement of each type of SHS emission difficult in field settings and research documenting water-pipe SHS is greatly needed. Venues with a greater density of waterpipe smokers were found to have similar $\mathrm{PM}_{2.5}$ levels as venues with a greater density of cigarette smokers. The data suggest that water-pipe smoke emissions are an important source of indoor particulate pollution in public venues. Enforcement mechanisms are needed to ensure that ratifying nations conform to Article 8 of the FCTC. 
Acknowledgements Special thanks to Dr Ghazi Zaatari for his logistic support, Abir Farah for help in the field and to Hillel Alpert for helpful comments on the manuscript.

Funding This work was funded by grants from WHO, Beirut, Lebanonoffice to GS and the Flight Attendant Medical Research Institute to GNC. Additional funding and support provided by Framework Convention Alliance and Action on Smoking and Health International to GNC.

\section{Competing interests None.}

Contributors All authors have made substantial contributions to the design, implementation, analysis and/or writing of the manuscript.

Provenance and peer review Not commissioned; externally peer reviewed.

\section{REFERENCES}

1. US Department of Health and Human Services. The health consequences of involuntary exposure to tobacco smoke: a report of the Surgeon General. Atlanta, GA: US Department of Health and Human Services, Centers for Disease Control and Prevention, Coordinating Center for Health Promotion, National Center for Chronic Disease Prevention and Health Promotion, Office on Smoking and Health 2006.

2. National Toxicology Program. 11th Report on Carcinogens. Research Triangle Park, North Carolina: US Department of Health and Human Services, Public Health Service, 2005.

3. Maziak W, Rastam S, Ibrahim I, et al. Waterpipe associated particulate matter emissions. Nicotine Tob Res 2008;10:519-34.

4. WHO Study Group on Tobacco Product Regulation. Waterpipe tobacco smoking: health effects, research needs and recommended actions by regulators. http://www. who.int/tobacco/global interaction/tobreg/waterpipe/en/index.html laccessed 30 Sep 2009).

5. Smith-Simone S, Maziak W, Ward KD, et al. Waterpipe tobacco smoking: knowledge, attitudes, beliefs, and behavior in two U.S. samples. Nicotine Tob Res 2008;10:393-8

6. Israel E, El-Setouhy M, Gadalla S, et al. Water pipe (Sisha) smoking in cafes in Egypt. J Egypt Soc Parasitol 2003;33(suppl 3):1073-85.

7. Shihadeh A, Saleh R. Polycyclic aromatic hydrocarbons, carbon monoxide, "tar", and nicotine in the mainstream smoke aerosol of the narghile water pipe. Food Chem Toxicol 2005:43:655-61.

8. Shihadeh A. Investigation of mainstream smoke aerosol of the argileh water pipe. Food Chem Toxicol 2003;41:143-52
9. Hyland A, Travers MJ, Dresler C, et al. A 32-country comparison of tobacco smoke derived particle levels in indoor public places. Tob Control 2008;17:159-65.

10. Monn Ch, Kindler P, Meile A, et al. Ultrafine particle emissions from waterpipes. Tob Control 2007:16:390-3.

11. WHO Air Quality guidelines for particulate matter, ozone, nitrogen dioxide, and sulfur dioxide. Global update 2005. http://whqlibdoc.who.int/hq/2006/ WHO SDE PHE OEH 06.02 eng.pdf (accessed 30 Sep 2009)

12. Dominici $\overline{\mathbf{F}}$, Peng $\mathrm{RD}$, , Bell $\overline{\mathrm{ML}}$, et al. Fine particulate air pollution and hospital admission for cardiovascular and respiratory diseases. JAMA 2006:295:1127-34.

13. Laden F, Schwartz J, Speizer FE, et al. Reduction in fine particulate air pollution and mortality: extended follow-up of the Harvard six cities study. Am J Respir Crit Care Med 2006:173:667-72.

14. World Health Organization. WHO framework convention on tobacco control. http:// www.who.int/tobacco/framework/WHO FCTC english.pdf (accessed 30 Sep 2009).

15. Repace J. Respirable particles and carcinogens in the air of delaware hospitality venues before and after a smoking ban. J Occup Environ Med 2004;46:887-905.

16. Repace JL, Hyde JN, Brugge D. Air Pollution in Boston bars before and after a smoking ban. BMC Pub Health 2006; 6:266

17. Travers MJ, Cummings $\mathrm{KM}$, Hyland $\mathrm{A}$, et al. Indoor air quality in hospitality venues before and after the implementation of a clean indoor air law-Western New York. MMWR Morb Mortal Wkly Rep 2003;53:1038-41.

18. Eisner MD, Smith AK, Blanc PD. Bartenders' respiratory health after establishment of smokefree bars and taverns. JAMA 1998:280:1909-14.

19. Menzies D, Nair A, Williamson PA, et al. Respiratory symptoms, pulmonary function, and markers of inflammation among bar workers before and after a legislative ban on smoking in public places. JAMA 2006;296:1742-8.

20. Dinno A, Glantz S. Clean indoor air laws immediately reduce heart attacks. Prev Med 2007:45:9-11.

21. Maziak W, Ward KD, Afifi Soweid RA, et al. Tobacco smoking using a waterpipe: a re-emerging strain in a global epidemic. Tob Control 2004;13:327-33.

22. Fong GT, Hyland A, Borland $\mathrm{R}$, et al. Reductions in tobacco smoke pollution and increases in support for smoke-free public places following the implementation of comprehensive smoke-free workplace legislation in the Republic of Ireland: findings from the ITC Ireland/UK Survey. Tob Control 2006:3(suppl 15):51-8.

23. Edwards R, Thomson $\mathrm{G}$, Wilson $\mathrm{N}$, et al. After the smoke has cleared: evaluation of the impact of a new national smoke-free law in New Zealand. Tob Control 2008;17:e2

24. Hyland A, Higbee C, Borland R, et al. Attitudes and beliefs about secondhand smoke and smoke-free policies in four countries: findings from the International Tobacco Control Four Country Survey.

25. Syria bans smoking in public places. http://news.bbc.co.uk/2/hi/middle_east/ 8302794.stm (accessed 23 Nov 2009). 